\title{
Less Screen Time, More Frequent Fruit and Vegetable Intake and Physical Activity are Associated with Greater Mental Wellbeing in Adolescents
}

\author{
Jenny Davison ${ }^{1} \mathbb{D} \cdot$ Brendan Bunting $^{1} \cdot$ Paul Connolly $^{2} \cdot$ Katrina Lloyd $^{3}$. \\ Laura Dunne ${ }^{3}$ Barbara Stewart-Knox ${ }^{4}$
}

Accepted: 31 January 2022/Published online: 8 February 2022

(c) The Author(s) 2022

\begin{abstract}
Wellbeing declines during adolescence, for which the reasons are unclear. This analysis explored associations between wellbeing and multiple lifestyle, socioeconomic and school-level factors in young people. Data were collected as part of the Wellbeing in School (WiSe) survey of adolescent school children in Northern Ireland at age $13-14$ years $(N=1618 ; 49 \%$ female $)$ and $15-16$ years $(N=1558 ; 50.5 \%$ female $)$. Wellbeing was assessed using the short-form Warwick-Edinburgh Mental Wellbeing Scale (sWEMWBS), where scores declined between time one (13-14 years) and time two (15-16 years) in both sexes and were significantly lower in females at both timepoints. Multilevel, multivariate modelling was therefore undertaken separately for males and females with sWEMWBS scores as the dependent variable. Physical activity, family affluence, fruit and vegetable intake, social media use, sleep duration, school factors (size and type) and religion were independent variables. More frequent physical activity in both sexes at both timepoints was associated with higher sWEMWBS scores. In females, higher sWEMWBS scores were associated with less social media use at time one (and marginally at time two), greater family affluence at time two, and being Catholic at both timepoints. In males, higher sWEMWBS scores were associated with more frequent fruit and vegetable intake at time one. Mental wellbeing was unrelated to sleep duration or school factors in either sex, at both time points. Efforts to maximize mental wellbeing in adolescents should promote engagement in physical activity and implement sex-specific interventions.
\end{abstract}

Keywords Mental wellbeing $\cdot$ Physical activity $\cdot$ Fruit and vegetables $\cdot$ Family affluence $\cdot$ Social media $\cdot$ Sleep

Jenny Davison

j.davison@ulster.ac.uk

Extended author information available on the last page of the article 


\section{Introduction}

Wellbeing has been designated a human right in Article 12 of the United Nations Convention of the Rights of the Child (OHCHR, 1989). Over the past decade, mental wellbeing has become increasingly important on public health and policy agendas across the world (Andreoni \& Galmarini, 2015; Dolan et al., 2011; Tedstone Doherty \& Kartalova-O’Doherty, 2010). There is no universally agreed definition of wellbeing and the term is often used interchangeably with life satisfaction, happiness and quality of life (Selwyn \& Riley, 2015; Statham \& Chase, 2010). What is agreed, however, is that wellbeing is multifaceted (Dodge et al., 2012; Delle et al., 2011; Forgeard et al., 2011) and encompasses both objective (e.g. income, education, health) and subjective (e.g. inter-personal relationships, autonomy) aspects of a person's life (Selwyn \& Riley, 2015; Bowling, 2011; Foregeard et al., 2011; Statham \& Chase, 2010).

While many different measures of wellbeing are used in surveys of young people, the vast majority suggest that wellbeing declines with age during adolescence (Gonzalez-Carrasco et al., 2017a, b; Dinisman \& Ben-Arieh, 2016; Klocke et al., 2014; Rees \& Dinisman, 2014; Gaspar et al., 2012; Rees et al., 2010). There is some evidence that adolescent girls experience lower wellbeing than boys (Gonzalez-Carrasco et al., 2017a; Rees \& Dinisman, 2014; Klocke et al., 2014; Gaspar et al., 2012; UNICEF Spain, 2012) and that this decrease in wellbeing over time is more pronounced in girls than boys (Meade \& Dowswell, 2016; The Children's Society, 2016). The reason for this trend is unclear but likely to be multifactorial, encompassing a range of individual, social and environmental factors (Davison et al., 2021, 2015a, b). Cross-sectional analysis of the Health Behaviour in School-aged Children (HBSC) study (Klocke et al., 2014) concluded that although individual level characteristics such as gender and age are important in explaining young people's wellbeing, social and environmental factors also contribute to wellbeing. A systematic review on children's wellbeing (Kidger et al., 2012) suggests a need for more studies measuring the effect of environmental and not just individual factors. This analysis, therefore, has explored a range of lifestyle, socioeconomic and school level factors with potential to impact upon adolescent wellbeing.

Approximately $30 \%$ of young people in the United Kingdom (UK) $(N=4899)$ engage in sporting activity every day (Booker et al., 2015). A growing body of evidence points to an association between greater physical activity and enhanced mental wellbeing in young people (Halliday et al., 2019; White et al., 2018). Recent research employing the WEMWBS has indicated that young people aged 11-20 years residing in Ireland $(N=5661)$ who engaged in sport had more positive mental wellbeing (Murphy et al., 2020). Cardiopulmonary fitness has also been associated with positive mental wellbeing (WEMWBS) in Australian 16-year-olds $(N=670)$ (Janssen \& LeBlanc, 2010). However, the evidence is not always clear cut. A longitudinal study of $(N=928)$ secondary schoolchildren (aged 13-16 years) found no association between physical activity (assessed via accelerometer) and mental wellbeing (WEMWBS) (Bell et al., 2019). A possible reason for this null finding could be due to sex differences in the association 
between wellbeing and physical activity, as adolescent females engage in physical activity less often than males and experience progressively lower wellbeing than males (Halliday et al., 2019; Murphy et al., 2020). It is possible, therefore, that lower physical activity and mental wellbeing are linked, particularly in girls.

Fruit and vegetable intake is considered a reliable marker of healthy eating (Taylor et al., 2020; Slavin \& Boyd, 2012). Evidence from longitudinal research in young people (aged $7-17$ years; $N=2630$ ) has implied a reciprocal relationship between unhealthy eating and poor mental wellbeing (Wu et al., 2019). Approximately $12-18 \%$ of young people consume a diet low in fruit and vegetables (de Oliveira Figueiredo, 2019; McKeown \& Nelson, 2018; Skardal et al., 2014; Zahra et al., 2014). Intake of fruit and vegetables tends to be lower among boys than girls (de Oliveira Figueiredo, 2019, Skardal et al., 2014; Post-Skagegard et al., 2002), and consumption reduces through adolescence (Post-Skagegard et al., 2002). Recent research in adolescents aged 13-16 years suggests that frequent fruit and vegetable consumption is associated with positive mental wellbeing (Davison et al., 2021).

Social media use has become increasingly important to young people and may impact upon wellbeing. A systematic review concluded that most studies (pre 2014) found no association between screen time and wellbeing (Best et al., 2014). Since then, a growing body of research has linked excessive social media use to lower wellbeing in young people (Booker et al., 2015, 2018; Jenkins et al., 2020; Naeemi \& Tamam, 2017; Straatmann et al., 2016; Viner et al., 2019; Young et al., 2020). Conversely, wellbeing has been shown to increase when young people abstain from social media (Brown \& Kuss, 2020). Detrimental effects of social media use appear more marked in girls (Booker et al., 2018; Hartas, 2019; Viner et al., 2019). That social media use is greater in girls, therefore, could be another factor contributing to the apparent lower wellbeing among adolescent girls compared to boys.

The recommended amount of sleep for young people is 8-10 h, however, research shows that many achieve less than $7 \mathrm{~h}$ of sleep per night (National Sleep Foundation, 2019). Potential consequences of excessive night-time social media use include shorter sleep duration, delayed bedtimes and later wake up times resulting in daytime tiredness (Carter et al., 2016; Twenge et al., 2017). Melatonin (natural hormone which helps control your sleep cycle) onset can be delayed by exposure to screens just before bed and that this can delay the onset of sleep (Chellappa et al., 2013). More than a third (37\%) of adolescent's report losing sleep subsequent to social media use close to bedtime (Espinoza, 2011). Studies of adolescents have found associations between screen usage and shorter sleep duration (Falbe et al., 2015; Lemola et al., 2015). There is increasing evidence of an association between shorter sleep duration and poorer mental wellbeing in adolescents (Royal College of Paediatrics \& Child Health, 2018; Shochat et al., 2014).

Among environmental factors that have been shown to be related to children's wellbeing, is socio-economic status (Gutman \& Feinstein, 2008). Young people in more socio-economically deprived circumstances are more likely to report lower wellbeing (Plenty \& Mood, 2016). Those in less affluent households are also more likely to report lower wellbeing (Simon et al., 2018). Review of the literature (Dinisman \& Ben-Arieh, 2016) concluded that while parental employment status was associated with children's wellbeing, measures such as low-income and material deprivation were 
not. More consistent findings emerged when children's own perceptions of their family financial status were considered. Those who thought they had fewer material goods or believed that their friends' families were better off than them had poorer wellbeing than their peers (Dinisman \& Ben-Arieh, 2016; Erhart et al., 2009). Therefore, this research has used the Family Affluence Scale (FAS) which is a self-report checklist of items owned by the family such as cars and computers and luxuries such as holidays.

There is a paucity of studies (post 1980) that have assessed the influence of school size and type on young people's mental wellbeing. A common assumption is that adolescents receive a superior experience, both intellectually and interpersonally, in smaller schools (Kidger et al., 2012; Watt, 2003). While research has explored the influence of school size on academic attainment (Govorova et al., 2020), it is not known how it relates to adolescent's wellbeing. Most existing studies consider the school ethos (i.e. processes and practices employed by the school) which have been found to explain barely $5 \%$ of the variation in pupil's wellbeing (Lazarides \& Buchholz, 2019; Murillo \& Hernández-Castilla, 2011). The current study considers school type (selective or comprehensive) as a potential factor related to wellbeing in young people.

Religiosity declines over the course of adolescence (Chan et al., 2015; Dew et al., 2020), although girls tend to be more religious than boys (Donahue \& Benson, 2010). Meta-analysis of pre-2010 data (Yonker et al., 2012) concluded an association between religiosity and wellbeing in adolescents $(N=66,273)$. Religion, therefore, has also been included in the current analysis.

Wellbeing is determined by an array of interacting individual, social and environmental factors (Davison et al., 2015a, b, 2021; Kidger et al., 2012; Klocke et al., 2014). In order to design and target interventions to promote wellbeing appropriately, it is important to understand multiple factors with potential to impact upon adolescent wellbeing over time. This analysis explored associations between a range of lifestyle (physical activity, fruit and vegetable intake, social media, sleep and religion), socioeconomic (family affluence) and school level (size and type) factors and wellbeing. It is predicted that mental wellbeing will be lower in females and will deteriorate over time to a greater degree in females. Given previous research, it is also hypothesised that mental wellbeing will vary by religion and school type and will be associated with less frequent fruit and vegetable intake, less physical activity, greater social media use and shorter sleep duration.

\section{Methods}

\subsection{Design and Participants}

Data were collected as part of the longitudinal Wellbeing in School (WiSe) study, which explored health and wellbeing of school children aged 11-16 years in Northern Ireland (NI). This analysis draws on data collected during in 2016 (time one) and 2018 (time two). The sample at time one (aged 13-14 years) comprised 1618 adolescents of whom $51 \%$ were male and $49 \%$ female, and at time two (aged 15-16 years) comprised continued participation of 1558 adolescents from time one of whom $49.5 \%$ were male and $50.5 \%$ female. 


\subsection{Procedure}

A list of all post-primary schools in Northern Ireland (NI) was obtained from the Department of Education NI (DENI) website. A letter detailing the aims, objectives and procedures of the study, along with an invitation to participate, was posted to each selected school. Of 203 schools contacted, 94 replied and 89 agreed to participate. Headteachers provided written consent for their school to participate after which they were provided with information sheets and consent forms to distribute to parents and pupils. Parents were given the opportunity to provide 'opt-out' consent of their child's participation. Pupils were required to provide full written consent prior to completing the questionnaire. At time two, all 89 schools were invited to re-participate in the study. Of the 89 schools, 79 were followed up at time two (response rate $89 \%$ ). Consent procedures described above were repeated at time two.

Fieldwork at time one and two was carried out in schools either on a study iPad or a computer, hosted by LimeSurvey, with a researcher (JD) present. At each school, one class in each year group participated.

\subsection{Measures}

\subsubsection{Short-Form Warwick-Edinburgh Mental Wellbeing Scale (sWEMWBS)}

The sWEMWBS (Tennant et al., 2007) was used to assess mental wellbeing. This measure comprises seven items designed to measure hedonic and eudemonic components of wellbeing. Each item is positively worded and scored on a 5-point Likert scale ranging from 'none of the time' (1) to 'all of the time' (5). Respondents are asked 'Please tick the box the best describes your experience of each over the last two weeks': 'I've been feeling optimistic about the future'; 'I've been feeling useful'; 'I've been feeling relaxed'; 'I've been dealing with problems well'; 'I've been thinking clearly'; 'I've been feeling close to other people'; and 'I've been able to make up my own mind about things'. The measure has undergone robust psychometric testing (Ringdal et al., 2018; Hunter et al., 2015; Clarke et al., 2011), has been validated in adolescents from across the United Kingdom (UK) and has been consistently found to have a unidimensional factor structure (Hunter et al., 2015; Melendez-Torres et al., 2019; Stewart-Brown et al., 2009; Tennant et al., 2007). Scores can range from 7 to 35 , with higher scores indicating higher wellbeing.

A model-based approach was taken to the estimation of reliability (Yang \& Green, 2011). This has the advantage that the underlying measurement model used in the evaluation of the sWEMWBS can be directly used to evaluate the model, rather than use a test for reliability that is likely to have been based on different model assumptions. Estimates of reliability were based on robust maximum likelihood (MLR) and weighted least squares mean \& variance (WLSMV). Using the MLR approach, the estimated reliability for females at time one was $0.79(\mathrm{SE}=0.013)$ and at time two $0.77(\mathrm{SE}=0.015)$. Comparable values for males were $0.70(\mathrm{SE}=0.022)$ and 0.76 $(\mathrm{SE}=0.021)$. The nonlinear (WLSMV) model values for reliability were all $0.3-0.4$ higher than for the MLR based estimates. 


\subsubsection{Family Affluence Scale (FAS)}

The family affluence scale (FAS) (Boyce et al., 2006) is an indicator of socio-economic inequality in young people aged 14-17 years old which has been validated in samples across Europe $(N=10,900)$ (Moor et al., 2019). The FAS comprises four items: 'Do you have your own bedroom at home where you normally live?' for which responses are dichotomous (yes/no); 'Does your family own a car, van or truck?' for which responses are 'yes-one, yes-two or more, or no'; 'During the past 12 months how many times did you travel away on holiday with your family?' for which responses are - 'not at all, once, twice, more than twice'; and. 'How many computers, laptops, tablets or iPads do your family own?' for which responses are 'none, one, two, three or more'. Total scores can range from $4-13$ with higher scores representing greater family affluence.

Principal component analysis was used to optimise the relationship between the items and the underlying component under evaluation (family affluence). From this emergent model a component weight was obtained for each individual using SPSS v25. These were then used within the statistical analyses. This use of a linear composite indicators is in keeping with measurement recommendations (Bollen \& Lennox, 1991).

\subsubsection{Fruit and Vegetable Intake}

The frequency with which fruit and vegetables were consumed was measured via a single item which asked 'how many portions of fruit/vegetables (including fresh, dried, tinned, juiced and frozen) do you usually eat each day?' for which responses were on a seven-point scale ranging from none (1) to more than 5 (7), with higher scores indicating greater frequency.

\subsubsection{Physical Activity Questionnaire for Older Children (PAQ-C) and Adolescents (PAQ-A)}

The Physical Activity Questionnaire for Older Children (PAQ-C) (Crocker et al., 1997 ) is a self-administered seven-day recall questionnaire to assess overall participation in physical activity and has been designed for use with children aged 8 to 14 years. PAQ-C was used at Time 1 (age 13/14 years) and consists of nine questions structured to discern low (1) to high (5) participation in physical activity during the previous seven days, with a tenth question to identify any who have engaged in unusual activity during the previous week. The first question contains an activity checklist of 22 items referring to common sports, leisure activities and games (Crocker et al., 1997). Two questions assess overall activity patterns during the week. Remaining items assess activity during specific periods of the day, including physical education (PE) class, morning break, lunchtime, after school, evening, and weekend. The Physical Activity Questionnaire for Adolescents (PAQ-A) (Kowalski et al., 1997) was used at Time 2 (age 15/16 years). The PAQ-A is designed for use with adolescents aged 14 to 20 years and consists of nine questions identical to the PAQ-A with the question concerning morning break excluded. Responses to questions are on a scale from 1 to 5 with higher scores indicating greater activity. Both 
the PAQ-C and PAQ-A were scored according to the manual (Kowalski et al., 1997). The average of items is used to create a PAQ summary score.

\subsubsection{Social Media Use}

Social media use was measured by a single item which asked 'On a normal school day, how many hours were you active on social media (i.e. from you wake to you sleep again)?' for which response options were: (1) Less than one hour; (2) Around $1 \mathrm{~h}$; (3) Around $2 \mathrm{~h}$; (4) Around $3 \mathrm{~h}$; (5) Around 4 h; (6) Around 5 h; (7) Around $6 \mathrm{~h}$; (8) $7 \mathrm{~h}$ or more.

\subsubsection{Sleep}

Sleep duration was assessed using two questions 'On a normal school night, what is your bedtime?' and 'On a school day, what is your wake time?'. A variable indicating total hours of sleep per night was calculated from the difference between bedtime and waketime.

\subsubsection{Religion}

Religion was recorded by a single item, asked at time two: 'Which of the following do you consider yourself to belong to?' for which response options were: (1) Protestant community (37\%; $n=573)$; (2) Catholic community $(52 \% ; n=811)$; and, (3) Other $(11 \% ; n=171)$.

\subsection{Statistical Analysis}

Given that wellbeing trajectories differ by sex (Gonzalez-Carrasco et al., 2017a; Meade \& Dowswell, 2016; The Children's Society, 2016; Rees \& Dinisman, 2014; Klocke et al., 2014; Gaspar et al., 2012; UNICEF Spain, 2012), sex differences were examined by constructing separate multilevel, multivariate models for males and females. Physical activity (PAQ), family affluence (FAS), social media use (hours per day), religion (Catholic/Protestant/Other), sleep (hours per night) school size (number of pupils) and frequency of fruit and vegetable intake (7-point Likert scale) were entered into the model as independent variables. Mental wellbeing (sWEMWBS) scores were taken as the dependent variable in both models. School type was entered as a cluster variable. Interactions between all independent variables were built into the model. The $P=0.05$ level was taken as significant.

A five-point Likert scale was used to record responses to the sWEMWBS. This ordinal scale was analysed using weighted least square parameter estimates with a mean and variance-adjusted chi-square test statistic (WLSMV), using the Mplus 8.5 software (Muthén \& Muthén, 1998-2017) version 8.4. This method of estimation provides a model-based approach to missing data under the assumption of missing at random 
(MAR). Standard errors and fit statistics were adjusted for the non-independence of students within schools.

The factor model based on the sWEMWBS was used as the outcome measure for separate analyses on the data from the first and second occasion. This model maintained the constraints shown to describe the sWEMWBS model, and for practical purposes the thresholds for both item 3 and item 6 were left unconstrained. A series of predictors were then included within the model measures on both occasions. To examine the potential differences between the effect for females and males, the analysis on both occasions was conducted using a multigroup approach for the sex variable.

A test was also conducted of the effects of occasion (time) and sex of respondents. For this analysis a mixed type ANOVA with correction for measurement error was used, where time represented the data on either the first or second occasion and sex was represented using a dichotomous measure. The sWEMWBS, as with all the models was analysed using all seven observed measures within a latent variable structure, hence allowing for a correction for measurement error. This was achieved by structuring data in a long format, and again taking into account the clustering effect of school.

\section{Results}

\subsection{Measurement Invariance: sWEMWBS Replication on Two Occasions (Separately for Females and Males)}

To test for factorial invariance of female and male responses to the items contained within the sWEMWBS, data from time two were analysed first, as it could be expected to be more stable. In this model the factor loadings and the thresholds relating to the seven items were constrained to be equal across the groups. Because a correlation had been introduced between items one (I've been feeling optimistic about the future) and two (I've been feeling useful) in the previous model, this was also kept in the invariant version of the model. This model, using a weighted least square mean and variance adjusted (WLSMV) estimator, provided a reasonable description of the model: root mean square error of approximation $(\mathrm{RMSEA})=0.06,90 \%$; confidence interval $(\mathrm{CI})=0.06-0.07$; Comparative Fit Index $(\mathrm{CFI})=0.96$; Tucker-Lewis Index $(\mathrm{TLI})=0.97$; and, standardised root mean square residual $(\mathrm{SRMR})=0.03$. From an examination of the modification indices (MI) it was evident that there was room for improvement in the fit criteria based on the threshold values in relation to item three (I've been feeling relaxed). This change resulted in slight improvement to the model fit statistics (RMSEA $=0.05,90 \%$ CI: 0.04-0.06; CFI $=0.98$, TLI $=0.98$; SRMR $=0.02$ ). The unstandardised factor loadings, which were restricted to be equal for females and males, were as follows: 1.00, 1.12, 1.02, 1.30, 1.39, 1.02, \& 1.08. The respective standardised factor loading can vary for those in both groups as a result of different covariate variances. The standardised factor loadings for females were: 0.55 , $0.62,0.56,0.71,0.76,0.56 \& 0.59$. For males the values were: $0.54,0.62,0.53,0.72$, $0.75,0.57, \& 0.61$. 
At time one where the model from the time two was imposed on the data, i.e. equal factor loadings and thresholds (with the exception of item three) were restricted to be invariant, along with an invariant covariance between the residual variance for items one (I've been feeling optimistic about the future) and two (I've been feeling useful), the model provided an adequate explanation for the data (RMSEA $=0.05,90 \%$ CI: 0.04-0.06; CFI =0.98, TLI =0.98; SRMR =0.03). From an examination of the fit indices there was a suggestion that the thresholds relating to item six (I've been feeling close to other people) could be relaxed across the groups, with the highest modification being MI: 37.8 in both groups. With this alteration the fit statistics were $(\mathrm{RMSEA}=0.04,90 \% \mathrm{CI}$ : $0.03-0.05$; $\mathrm{CFI}=0.99$, TLI $=0.98$; $\mathrm{SRMR}=0.02$ ). The model recorded threshold indicates the expected value of the latent variable (factor) at which an individual in a given group transitions from a value of 0 to a value of 1 , in the current case on an ordinal scale. The unstandardised factor loadings were 1.00, 1.24, 1.24, 1.43, 1.50, 1.22 \& 1.18, for items one to seven. The respective standardised factor scores for females were: $0.51,0.63,0.64,0.73$, $0.77,0.62$, \& 0.60 and for males: $0.41,0.55,0.53,0.63,0.69,0.52, \& 0.54$.

It was therefore evident that a one-factor model was an adequate description for these data, though there was some evidence for a differential pattern of responding, depending on one's sex and the timepoint (i.e. age). The factor mean associated with females at time one (age 13-14 years) was set at zero (i.e. the factor mean) and its difference from the factor mean for males tested using a $\mathrm{z}$-distribution $(\mathrm{Est}=0.22$, $\mathrm{se}=0.035$, Est $/ \mathrm{SE}=6.221$, p-value $=0.000$ ). At time two (age 15-16 years) males again had a higher average score on the $\mathrm{sWEMWBS}(\mathrm{Est}=0.256$. $\mathrm{se}=0.038$, Est $\mathrm{SE}=6.803, p$-value $=0.000)($ Fig. 1$)$.

\subsection{Predictors of Mental Wellbeing on Two Separate Occasions}

Mental wellbeing, as assessed by the theoretical model underlying the sWEMWBS, was regressed onto a number of predictor measures (physical activity; fruit and vegetable intake; sleep; social media; family affluence; and, religion). To maintain equality restrictions between the responses from females and males on the sWEMWBS, the regression model was conducted within a multi-group framework. Predictor variables were freely estimated for females and males. The fit statistics at time one (RMSEA $=0.03,90 \%$ CI: 0.02-0.03; CFI $=0.97$, TLI $=0.97$; SRMR $=0.1$ ) indicated that female and male responses to the sWEMWBS were as seen previously essentially responding in a factorially invariant manner. The correlated residual between the first and second item was maintained with the sWEMWBS part of the model and the threshold for items three and six were left unconstrained. The identical model at time two also indicated that there was no interaction between sex and the effects of a range of predictors on mental wellbeing (RMSEA $=0.03,90 \% \mathrm{CI}$ : 0.03-0.04; CFI $=0.97$, TLI =0.96; SRMR $=0.09$ ). 


\subsection{Determinants of Mental Wellbeing (sWEMWBS) on Two Cross-Sectional Occasions for Females}

More frequent physical activity and religion (being Catholic) at both time one (age $13-14$ years $)(P<0.001)$ and time two (age $15-16$ years $)(P=0.001)$ was associated with higher mental wellbeing in females (see Table 1). Greater family affluence at time two $(P<0.001)$ was associated with higher mental wellbeing in females. Greater social media use at time one $(P=0.002)$ and marginally greater social media use at time two $(P=0.058)$ was associated with lower mental wellbeing in females. Being Protestant at time one $(P=0.003)$ and time two $(P=0.013)$ or of 'other' religion at time one $(P=0.041)$ and time two $(P<0.001)$ also associated with female's lower mental wellbeing.

\subsection{Determinants of Mental Wellbeing (sWEMWBS) on Two Cross-Sectional Occasions for Males}

More frequent physical activity at both time one (age 13-14 years) $(P=0.022)$ and time two (age 15-16 years) $(P=0.040)$, and more frequent fruit and vegetable intake at time one (age 13-14 years) $(P=0.015)$ was associated with higher mental wellbeing in males (see Table 2).

\subsection{Mental Wellbeing (sWEMWBS), Interaction of Time (Occasions) by Sex (Mixed ANOVA with Correction for Measurement Error)}

This test of the interaction between time (i.e. age) and sex indicated a statistically significant decline in sWEMWBS scores between time one (aged 13-14 years $/ N=1618$ ) $(\mathrm{M}=3.70 ; \mathrm{SD}=0.56)$ and time two (aged $15-16$ years $/ N=1558)(\mathrm{M}=3.60 ; \mathrm{SD}=0.60)$ in the sample as a whole (see Table 3), with model estimated values as follows (Est $=-0.059$; se $=0.019$; Est $/ \mathrm{SE}=-3.088 ; P=0.002)$. sWEMWBS scores were significantly lower in females than males $(\mathrm{Est}=-0.145 ; \mathrm{se}=0.025 ; \mathrm{Est} / \mathrm{SE}=-5.846 ; P<0.000)$ (Fig. 2).

\section{Discussion}

We investigated multiple factors contributing to mental wellbeing longitudinally in a cohort of adolescents aged 13-16 years. The findings confirmed results of previous research (Booker et al., 2018; Burke \& Minton, 2019; Chen \& VanderWeele, 2018; Clarke et al., 2011), wellbeing declined between the ages of 13 and 16 years in both sexes. Also consistent with previous research using the sWEMWBS (Bell et al., 2019; McKay \& Andretta, 2017; Campbell-Jack, Hinchcliffe \& Rutherford, 2015; Clarke et al., 2011), mental wellbeing was lower in females. These findings, however, contradict other research using the sWEMWBS (Hunter et al., 2015) that found no change in mental wellbeing between the 13 and 16 years of age. Given mental wellbeing is culturally specific (Tennant et al., 2007) and that Hunter and colleagues 


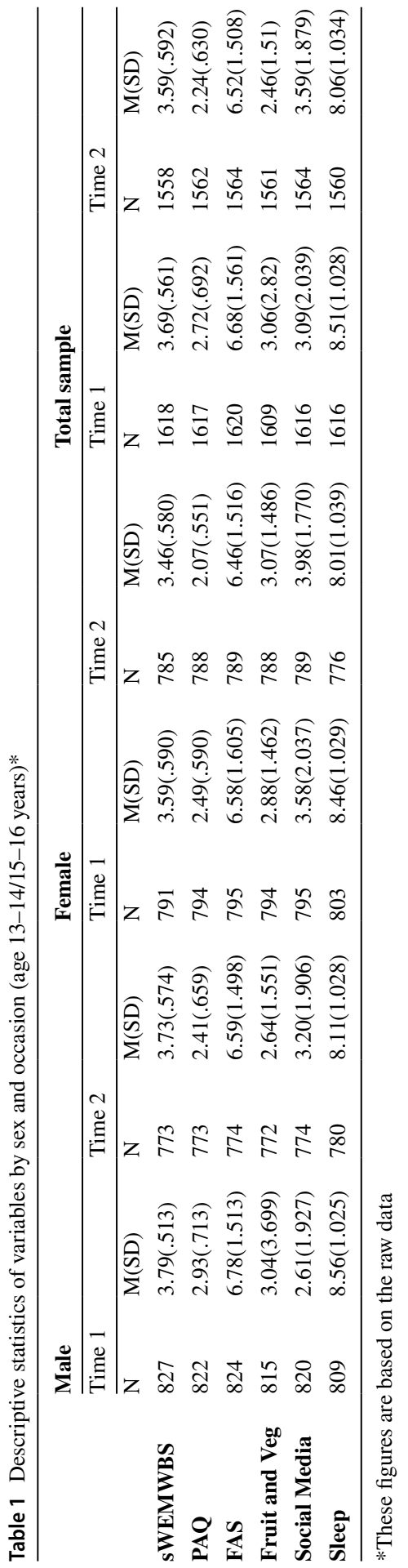


Table 2 Predictors (unstandardized) of mental wellbeing in females at time point $1(n=791)$ and $2(n=785)$

\begin{tabular}{|c|c|c|c|c|c|c|c|c|}
\hline & \multicolumn{2}{|c|}{ Estimate (Est) } & \multicolumn{2}{|c|}{$\begin{array}{l}\text { Standard Error } \\
(\mathrm{SE})\end{array}$} & \multicolumn{2}{|l|}{ Est/SE } & \multicolumn{2}{|c|}{$P$ Value } \\
\hline & $T 1$ & $T 2$ & $T 1$ & $T 2$ & $T 1$ & $T 2$ & $T 1$ & $T 2$ \\
\hline Age (months) & -0.074 & 0.029 & 0.077 & 0.064 & -0.962 & 0.446 & 0.336 & 0.656 \\
\hline Family Affluence & 0.046 & 0.101 & 0.025 & 0.024 & 1.836 & 4.220 & 0.066 & 0.000 \\
\hline Physical Activity & 0.249 & 0.179 & 0.041 & 0.054 & 6.070 & 3.292 & 0.000 & 0.001 \\
\hline Social Media (hrs) & -0.039 & -0.025 & 0.012 & 0.013 & -3.119 & -1.892 & 0.002 & 0.059 \\
\hline Fruit/Veg Intake & 0.001 & 0.014 & 0.019 & 0.015 & 0.038 & 0.983 & 0.970 & 0.326 \\
\hline School size & 0.003 & 0.000 & 0.005 & 0.007 & 0.550 & -0.034 & 0.583 & 0.973 \\
\hline Free School Meals & -0.004 & 0.017 & 0.023 & 0.029 & -0.160 & 0.585 & 0.873 & 0.559 \\
\hline School Type & 0.079 & 0.050 & 0.074 & 0.089 & 1.077 & 0.566 & 0.281 & 0.571 \\
\hline Religion Protestant & -0.152 & -0.127 & 0.051 & 0.051 & -2.971 & -2.479 & 0.003 & 0.013 \\
\hline Religion Other & -0.187 & -0.330 & 0.092 & 0.072 & -2.047 & -4.557 & 0.041 & 0.000 \\
\hline
\end{tabular}

Est/SE estimate divided by standard error; $* * p<0.001 ; * p<0.005$

(2015) study comprised a sample of rural Australian adolescents, this disparity in results may reflect differences in educational and recreational experiences (Quine et al., 2003).

The sWEMWBS as a one factor model provided an adequate description of the data that was consistent with previous studies using the sWEMWBS to assess mental wellbeing in adolescents (Clarke et al., 2011; McKay \& Andretta, 2017; Melendez-Torres et al., 2019). We found that the sWEMWBS performed differently for males and females. Females scored lower than males on sWEMWBS item three 'feeling relaxed' and item six 'feeling close to other people'. Males and females, therefore, were modelled separately. There were inter-item differences in responses such that scores on 'feeling optimistic' and 'feeling useful' increased

Table 3 Predictors (unstandardized) of mental wellbeing in males at time point $1(n=827)$ and $2(n=773)$

\begin{tabular}{|c|c|c|c|c|c|c|c|c|}
\hline & \multicolumn{2}{|c|}{ Estimate (Est) } & \multicolumn{2}{|c|}{$\begin{array}{l}\text { Standard Error } \\
\text { (SE) }\end{array}$} & \multicolumn{2}{|l|}{ Est/SE } & \multicolumn{2}{|c|}{$P$ Value } \\
\hline & $T 1$ & $T 2$ & $T 1$ & $T 2$ & $T 1$ & $T 2$ & $T 1$ & $T 2$ \\
\hline Age (months) & -0.074 & -0.266 & 0.044 & 0.169 & -1.659 & -1.571 & 0.097 & 0.116 \\
\hline Family Affluence & 0.016 & 0.02 & 0.013 & 0.037 & 1.241 & 0.617 & 0.215 & 0.537 \\
\hline Physical Activity & 0.064 & 0.275 & 0.031 & 0.139 & 2.051 & 1.981 & 0.040 & 0.048 \\
\hline Social Media (hrs) & -0.006 & -0.043 & 0.006 & 0.026 & -0.998 & -1.659 & 0.318 & 0.097 \\
\hline Fruit/Veg Intake & 0.038 & 0.038 & 0.018 & 0.029 & 2.107 & 1.302 & 0.035 & 0.193 \\
\hline School size & 0.003 & 0.020 & 0.004 & 0.014 & 0.855 & 1.401 & 0.393 & 0.161 \\
\hline Free School Meals & 0.002 & 0.052 & 0.013 & 0.040 & 0.144 & 1.310 & 0.885 & 0.190 \\
\hline School Type & 0.014 & -0.025 & 0.048 & 0.115 & 0.295 & -0.218 & 0.768 & 0.828 \\
\hline Religion Protestant & -0.055 & 0.082 & 0.042 & 0.084 & -1.306 & 0.975 & 0.192 & 0.330 \\
\hline Religion Other & -0.048 & -0.093 & 0.047 & 0.118 & -1.032 & -0.787 & 0.302 & 0.432 \\
\hline
\end{tabular}

Est/SE estimate divided by standard error; ** $p<0.001 ; * p<0.005$ 


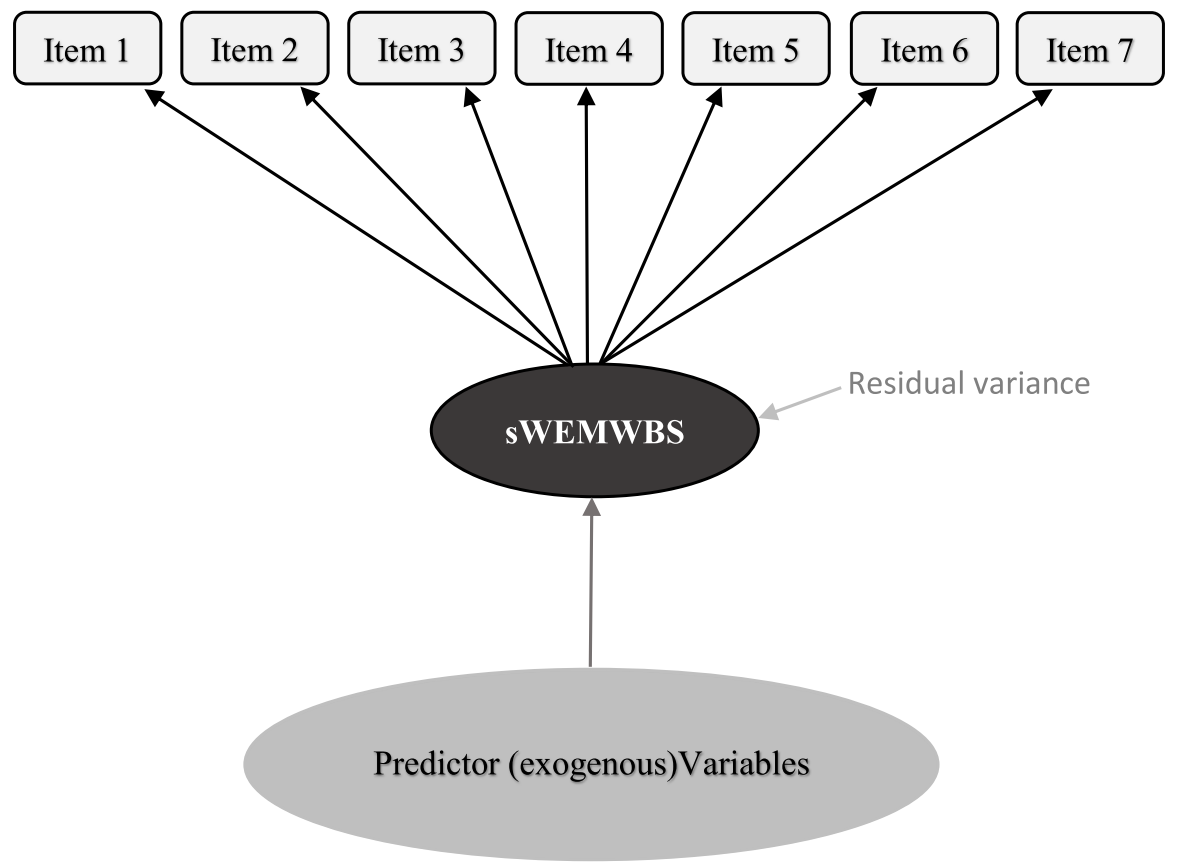

Fig. 1 Heuristic diagram illustrating the seven observed sWEMWBS items explained by a latent construct (mental wellbeing) which in turn was explained by a number of predictors

significantly over time. The correlated residual between these items was robust across the analyses. This may be because of high cognitive association prompted by the wording in these items or a serial order effect. Subsequent analyses, therefore, sought to explain apparent changes in wellbeing between time points. Given wellbeing is likely to be multi-factorially determined (Davison et al., 2015a, b, 2021), potential explanatory variables analysed related to lifestyle (physical activity, fruit and vegetable intake, social media use, sleep duration, religion), socio-economic circumstances (family affluence), and school size and type.

Consistent with previous research on physical activity and/or fitness and mental wellbeing assessed using the sWEMWBS in Ireland (Murphy et al., 2020) and in Australia (Janssen et al., 2020), higher mental wellbeing was associated with more frequent physical activity for both males and females at both time points. Contrary to our prediction, but in keeping with other research in school children aged 13-16 years conducted in the UK using the WEMWBS (Bell et al., 2019), there were no sex differences in the link between physical activity and wellbeing. These results imply that physical activity should be promoted among adolescents to maximise wellbeing.

A growing body of research has linked social media use to lower wellbeing in young people (Booker et al., 2015, 2018; Naeemi \& Tamam, 2017; Straatmann et al., 2016; Viner et al., 2019; Young et al., 2020). Consistent with evidence that social media is detrimental to wellbeing in girls (Booker et al., 2018; Hartas, 2019; 


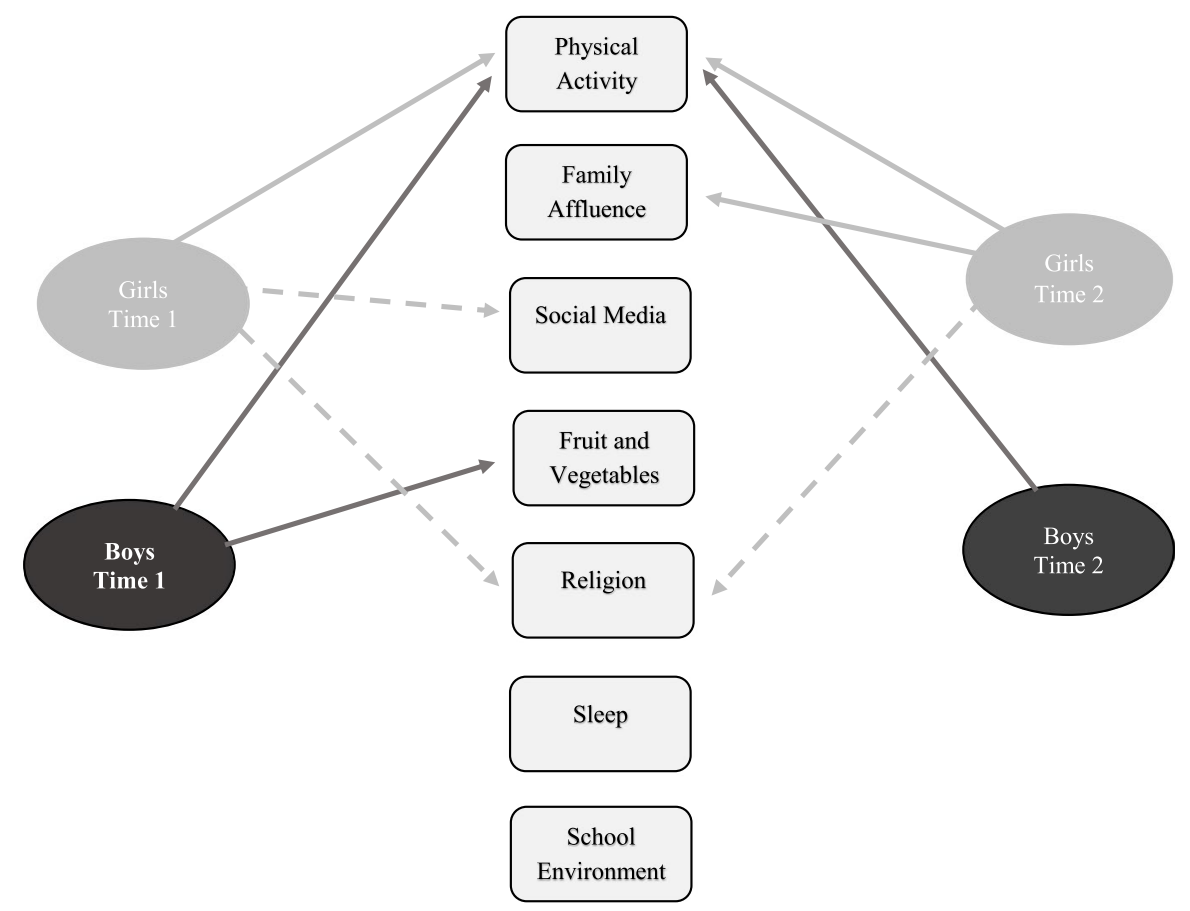

Fig. 2 Associations between mental wellbeing (sWEMWBS) and lifestyle factors, in both sexes on both occasions

Viner et al., 2019), the current analysis also indicated that greater social media use was associated with lower mental wellbeing in females but not males. The lack of association among males perhaps suggests sex differences in social media use and impact upon wellbeing (Booker et al., 2018). Unlike previous surveys of young people which found the relationship between social media use and lower wellbeing to persist in girls aged 13-15 years (Booker et al., 2018; Hartas, 2019; Viner et al., 2019), the association between social media use and wellbeing in girls in the current sample was only marginal $(P=0.058)$ by the age of $15-16$ years. This disparity could reflect differences in how wellbeing has been measured as none of these previous studies employed the sWEMWBS. Given evidence that mental wellbeing improves when young people abstain from social media (Brown \& Kuss, 2020), this finding implies that to promote wellbeing it may be necessary to advise younger adolescent females to restrict time spent on social media.

Young people consume a diet low in fruit and vegetables (Davison et al., 2015a, b; de Oliveira Figueiredo et al., 2019; Howe et al., 2016; McKeown \& Nelson, 2018; Zahra et al., 2014) and intakes tend to be lower in adolescent males than females (de Oliveira Figueiredo et al., 2019; Post-Skagegard et al., 2002; Skardal et al., 2014). Our results indicated that more frequent fruit and vegetable intake was associated with higher mental wellbeing, but only in boys and only at age 13-14 years. This is consistent with previous longitudinal research (Wu et al., 2019) and qualitative enquiry (Davison et al., 2015a) implying a reciprocal relationship between wellbeing 
and healthy eating in young people. The observed age and sex difference in the association between wellbeing and intake could be because the frequency with which fruit and vegetables were consumed was higher in girls than boys at age 13-14 years (Table 3). The finding that the frequency of fruit and vegetable intake decreased with increasing age during adolescence is consistent with previous research (Silva et al., 2020). Intervention to improve wellbeing in adolescent males should seek to encourage greater consumption of fruit and vegetables.

Consistent with previous meta-analysis implying that religiosity is protective of wellbeing in young people (Yonker et al., 2012), mental wellbeing was higher in girls of Catholic faith and this association was evident at both time points (age 13-14 and 15-16 years). Girls tend to be more religious than boys (Donahue \& Benson, 2010), and possible mediating factors include peers, values and social norms (Hardy et al., 2019). Given the Northern Ireland school system is segregated by religion, it is difficult to separate out the effects of school culture which may affect relationships with peers, values and social norms or regional influences (Gutman \& Feinstein, 2008; Moore et al., 2020). Although 7\% of schools surveyed were integrated by religion, a sizeable proportion were religious-based schools. Apparent religious differences may be the result of socio-economic and cultural differences between schools or school catchment areas.

Mental wellbeing was associated with lower family affluence in girls but only when older (age 15-16 years). This agrees with previous research linking lower family affluence to lower wellbeing (Dinisman \& Ben-Arieh, 2016; Erhart et al., 2009; Simon et al., 2018). Unlike other measures of deprivation, the FAS focusses on the visible trappings of wealth, which these data suggest only become salient to girls once they reach age 15-16 years, at which point they judge their family's affluence relative to their peers with potential detriment to wellbeing (Dinisman \& Ben-Arieh, 2016). This sex-specific developmental-factor could explain previous mixed, often contradictory, results on affluence and wellbeing in young people.

Contrary to previous research (Royal College of Paediatrics \& Child Health, 2018; Shochat et al., 2014) sleep duration was not associated with mental wellbeing. This finding was unexpected given the high levels of social media usage reported in our sample, and existing evidence for a putative link between excessive social media use, particularly when it occurs later in the day, and sleep quality and quantity (Espinoza, 2011; Falbe et al., 2015; Lemola et al., 2015). Despite existing evidence to suggest that school-level factors (Moore et al., 2020), such as larger school size (Kidger et al., 2012), can be detrimental to adolescent mental wellbeing, this analysis found no evidence for an association between school type and size, and mental wellbeing in either sex, irrespective of age.

These findings enhance our understanding of mental wellbeing in young people. Although well-validated psychometric measures have been employed to assess wellbeing and explanatory variables, the findings may be subject to limitations inherent in self-reported data such as inaccurate recall and bias toward what is perceived to be socially acceptable (Rosenman et al., 2011). The sWEMWBS is a valid and reliable measure of mental wellbeing which accounts for both hedonic and eudemonic elements of positive wellbeing and is suitable for use in large samples (Clarke et al., 2011; Hunter et al., 2015; Ringdal et al., 2018). The FAS which was used to 
assess socio-economic status is appropriate for evaluating adolescents' family affluence (Hobza et al., 2017; Erhart et al., 2009). That physical activity was assessed by questionnaire (PAQ) rather than accelerometer and that single item measures were used to assess social media use and sleep duration, however, may have affected the accuracy of data collected. Among strengths is the large sample size representing nearly half of the post-primary schools in Northern Ireland and that the analysis has taken into account the clustered nature of data at school level. This study addresses the paucity of longitudinal data on young people's wellbeing (Winpenny et al., 2017) and limitations often levied at the over-use of cross-sectional surveys (FerrerCascales et al., 2019). Given this is a survey, albeit at two points in time, it is difficult to establish whether mental wellbeing is a cause or an effect of physical activity, social media use, or fruit and vegetable intake in adolescents, or to determine the degree to which the relationships are circular. Family affluence and religion, however, are social factors which are known to contribute to wellbeing in young people (Maenhout et al., 2020; Simon et al., 2018; Yonker et al., 2012) and which can be addressed to enhance wellbeing.

\section{Conclusions}

Our findings imply that interventions aimed at improving mental wellbeing in young people, should promote physical activity among all adolescents, target females in less affluent households, curtail social media use, and promote the consumption of fruit and vegetables in males. These findings emphasise the need for sex-specific mental wellbeing promotion interventions (Lombardo et al., 2019). While this study has provided a first step in identifying determinants of mental wellbeing in adolescence longitudinally at ages 13-14 and 15-16 years, further continued longitudinal research is required to map mental wellbeing throughout adolescence (age 10 to 19 years) and to explore how young people's wellbeing develops over time. Qualitative enquiry could be valuable in providing contextual understanding of contributing factors. These findings should be of interest to key stakeholders seeking to promote wellbeing in young people.

Abbreviations FAS: Family Affluence Scale; sWEMWBS: Short-form Warwick-Edinburgh Mental Wellbeing Scale; WiSe: Wellbeing in Schools study; PAQ: Physical activity questionnaire.

Acknowledgements We wish to thank all the schools who made this study possible, and all of the pupils who gave of their time to participate.

Author Contribution PC and KL were responsible for the conception of the research idea. PC, KL, LD and JD contributed to the study design and management. JD lead data collection and preparation of the project dataset. JD, BSK and BB formulated the research questions and contributed to the design of the analysis. BB undertook the analysis. JD, BSK and BB were involved in drafting the paper. All authors reviewed the manuscript and approved the final version submitted for publication.

Funding This research did not receive any specific grant from funding agencies in the public, commercial, or not-for-profit sectors. This material is based upon work conducted as part of the Wellbeing in Schools (WiSe) study which was financially supported by the Centre of Excellence for Public Health (Northern Ireland), and the Centre of Evidence and Social Innovation, at Queens University Belfast. 
Availability of Data and Materials The dataset analysed during the current student is available from the corresponding author on reasonable request.

Code Availability Not applicable.

\section{Declarations}

Ethics Approval This study obtained ethical approval from the School of Education Research Ethics Committee, Queens University Belfast (reference numbers 100314 and 111217). The study was performed in accordance to the Declaration of Helsinki.

Consent to Participate Parental consent was obtained for all participants, and participants gave informed consent (assent) prior to taking part in the study.

Consent for Publication Not applicable.

Conflicts of Interest The authors declare that they have no conflict of interests or competing interests.

Open Access This article is licensed under a Creative Commons Attribution 4.0 International License, which permits use, sharing, adaptation, distribution and reproduction in any medium or format, as long as you give appropriate credit to the original author(s) and the source, provide a link to the Creative Commons licence, and indicate if changes were made. The images or other third party material in this article are included in the article's Creative Commons licence, unless indicated otherwise in a credit line to the material. If material is not included in the article's Creative Commons licence and your intended use is not permitted by statutory regulation or exceeds the permitted use, you will need to obtain permission directly from the copyright holder. To view a copy of this licence, visit http://creativecommons.org/licen ses/by/4.0/.

\section{References}

Andreoni, V., \& Galmarini, S. (2015). Mapping the distribution of Well-Being in Europe beyond national borders. Luxembourg: Publications Office of the European Union. https://publications. jrc.ec.europa.eu/repository/handle/JRC86661

Bell, S. L., Audrey, S., Gunnell, D., Cooper, A., \& Campbell, R. (2019). The relationship between physical activity, mental wellbeing and symptoms of mental health disorder in adolescents: A cohort study. International Journal of Behavioral Nutrition and Physical Activity, 16, 138. https://doi.org/10.1186/s12966-019-0901-7

Best, P., Manktelow, R., \& Taylor, B. (2014). Online communication, social media and adolescent wellbeing: A systematic narrative review. Children and Youth Services Review, 41, 27-36. https://doi.org/10.1016/j.childyouth.2014.03.001

Bollen, K., \& Lennox, R. (1991). Conventional wisdom on measurement: A structural equation perspective. Psychological Bulletin, 110(2), 305-314. https://doi.org/10.1037/0033-2909.110.2.305

Booker, C. L., Kelly, Y. J., \& Sacker, A. (2018). Gender differences in the associations between age trends of social media interaction and well-being among 10-15 year olds in the UK. BMC Public Health, 18, 321. https://doi.org/10.1186/s12889-018-5220-4

Booker, C. L., Skew, A. J., Kelly, Y. J., \& Sacker, A. (2015). Media Use, Sports Participation, and Well-Being in Adolescence: Cross-Sectional Findings From the UK Household Longitudinal Study. American Journal of Public Health, 105(1), 173-179. https://doi.org/10.2105/AJPH.2013. 301783

Bowling, A. (2011). Do older and younger people differ in their reported well-being? A National Survey of Adults in Britain, Family Practice, 28, 145-155. https://doi.org/10.1093/fampra/cmq082 
Boyce, W., Torsheim, T., Currie, C., \& Zambon, A. (2006). The Family Affluence Scale as a Measure of National Wealth: Validation of an Adolescent Self-Report Measure. Social Indicators Research, 78, 473-487. https://doi.org/10.1007/s11205-005-1607-6

Brown, L., \& Kuss, D. J. (2020). Fear of Missing Out, Mental Wellbeing, and Social Connectedness: A Seven-Day Social Media Abstinence Trial. International Journal of Environmental Research and Public Health, 17(12), 4566. https://doi.org/10.3390/ijerph17124566

Burke, J., \& Minton, S. J. (2019). Well-being in post-primary schools in Ireland: The assessment and contribution of character strengths. Irish Educational Studies, 38(2), 177-192. https://doi.org/10. 1080/03323315.2018.1512887

Campbell-Jack, D., Hinchcliffe, S., \& Rutherford, L. (2015). The Scottish Health Survey: A National Statistics Publication for Scotland., Scottish Government, Edinburgh. https://www.gov.scot/publications/ scottish-health-survey-2015-volume-1-main-report/

Carter, B., Rees, P., Hale, L., Bhattacharjee, D., \& Paradkar, M. S. (2016). Association Between Portable Screen-Based Media Device Access or Use and Sleep Outcomes: A Systematic Review and Metaanalysis. JAMA Pediatrics, 170(12), 1202-1208. https://doi.org/10.1001/jamapediatrics.2016.2341

Chan, M., Tsai, K. M., \& Fuligni, A. J. (2015). Changes in Religiosity Across the Transition to Young Adulthood. Journal of Youth and Adolescence, 44(8), 1555-1566. https://doi.org/10.1007/s10964-014-0157-0

Chellappa, S. L., Steiner, R., Oelhafen, P., Lang, D., \& Gotz, T. (2013). Acute exposure to evening blueenriched light impacts on human sleep. The Journal of Sleep Research, 22, 573-580. https://doi.org/ 10.1111 jss. 12050

Chen, Y., \& VanderWeele, T. J. (2018). Associations of Religious Upbringing With Subsequent Health and Well-Being From Adolescence to Young Adulthood: An Outcome-Wide Analysis. American Journal of Epidemiology, 187(11), 2355-2364. https://doi.org/10.1093/aje/kwy142

Clarke, A., Friede, T., Putz, R., Ashdown, J., Martin, S., Blake, A., Adi, Y., Parkinson, J., Flynn, P., Platt, S., \& Stewart-Brown, S. (2011). Warwick-Edinburgh Mental Well-being Scale (WEMWBS): validated for teenage school students in England and Scotland. A mixed methods assessment. BMC Public Health, 11(1), 487. https://doi.org/10.1186/1471-2458-11-487

Crocker, P. R., Bailey, D. A., Faulkner, R. A., Kowalski, K. C., \& McGrath, R. (1997). Measuring general levels of physical activity: Preliminary evidence for the physical activity questionnaire for older children. Medicine and Science in Sports and Exercise, 29, 1344-1349. https://doi.org/10.1097/ 00005768-199710000-00011

Davison, J., Stewart-Knox, B., Connolly, P., Lloyd, K., Dunne, L., \& Bunting, B. (2021). Exploring the association between mental wellbeing, health-related quality of life, family affluence and food choice in adolescents. Appetite, 158, 105020. https://doi.org/10.1016/j.appet.2020.105020

Davison, J., Share, M., Hennessy, M., \& Stewart-Knox, B. (2015a). Caught in a 'spiral'. Barriers to healthy eating and dietary health promotion needs from the perspective of unemployed young people and their service providers. Appetite, 85, 146-154. https://doi.org/10.1016/j.appet.2014.11.010

Davison, J., Share, M., Hennessy, M., Bunting, B., Markovina, J., \& Stewart-Knox, B. (2015b). Correlates of food choice in unemployed young people: The role of demographic factors, self-efficacy, food involvement, food poverty and physical activity. Food Quality and Preference, 46, 40-47. https://doi.org/10.1016/j.foodqual.2015.06.014

Delle Fave, A., Brdar, I., Freire, T. et al. (2011). The Eudaimonic and Hedonic Components of Happiness: Qualitative and Quantitative Findings. Soc Indic Res 100, 185-207. https://doi.org/10.1007/ s11205-010-9632-5

de Oliveira Figueiredo, R. A., Viljakainen, J., Viljakainen, H., Roos, E., Rounge, T. B., \& Weiderpass, E. (2019). Identifying eating habits in Finnish children: A cross-sectional study. BMC Public Health, 19, 312. https://doi.org/10.1186/s12889-019-6603-x

Dew, R. E., Fuemmeler, B., \& Koenig, H. G. (2020). Trajectories of Religious Change From Adolescence to Adulthood, and Demographic, Environmental, and Psychiatric Correlates. The Journal of Nervous and Mental Disease, 208(6), 466-475. https://doi.org/10.1097/NMD.0000000000001154

Dinisman, T., \& Ben-Arieh, A. (2016). The Characteristics of Children's Subjective Well-Being. Social Indicators Research, 126(2), 555-569. https://doi.org/10.1007/s11205-015-0921-x

Dodge, R., Daly, A. P., Huyton, J., \& Sanders, L. D. (2012). The challenge of defining wellbeing. International Journal of Wellbeing, 2(3), 222-235. https://doi.org/10.5502/ijw.v2i3.4

Donahue, M. J., \& Benson, P. L. (2010). Religion and the Well-Being of Adolescents. Journal of Social Issues, 51(2), 145-160. https://doi.org/10.1111/j.1540-4560.1995.tb01328.x

Dolan, P., Layard, R., \& Metcalfe, R. (2011). Measuring Subjective Wellbeing for Public Policy: Recommendations on Measures. http://cep.lse.ac.uk/pubs/download/special/cepsp23.pdf 
Erhart, M., Ottova, V., Gaspar, T., Jericek, H., Schnohr, C., Alikasifoglu, M., et al. (2009). Measuring mental health and wellbeing of school-children in 15 European countries using the KIDSCREEN-10 Index. International Journal of Public Health, 54(Suppl. 2), 160-166. https://doi.org/10.1007/s00038-009-5407-7

Espinoza, G. (2011). The pervasiveness, connectedness, and intrusiveness of social network sites use among young adolescents. Cyberpsychology, Behavior and Social Networking, 14(12), 705-709. https://doi.org/10.1089/cyber.2010.0492

Falbe, J., Davison, K. K., Franckle, R. L., Ganter, C., Gortmaker, S. L., Smith, L., Land, T., \& Taveras, E. M. (2015). Sleep duration, restfulness, and screens in the sleep environment. Pediatrics, 135(2). https://doi.org/10.1542/peds.2014-2306

Ferrer-Cascales, R., Albaladejo-Blazquez, N., Ruiz-Robledillo, N., Clement-Carbonell, V., Sanchez-SanSegundo, M., \& Zaragoza-Marti, A. (2019). Higher adherence to the mediterranean diet is related to more subjective happiness in adolescents: The role of health-related quality of life. Nutrients, 11, 698. https://doi.org/10. 3390/nu11030698

Forgeard, M. J. C., Jayawickreme, E., Kern, M., \& Seligman, M. E. P. (2011). Doing the right thing: Measuring wellbeing for public policy. International Journal of Wellbeing, 1(1), 79-106. https:// doi.org/10.5502/ijw.v1i1.15

Gaspar, T., Ribeiro, J. P., de Matos, M. G., Leal, I., \& Ferreira, A. (2012). Health-Related Quality of Life in Children and Adolescents: Subjective Well Being. The Spanish Journal of Psychology, 15(1), 177-186. https://doi.org/10.5209/rev_SJOP.2012.v15.n1.37306

Gonzalez-Carrasco, M., Casas, F., Malo, S., Vinas, F., \& Dinisman, T. (2017a). Changes with Age in Subjective Well-Being Through the Adolescent Years: Differences by Gender. Journal of Happiness Studies, 18, 63-88. https://doi.org/10.1007/s10902-016-9717-1

González-Carrasco, M., Casas, F., Viñas, F., Malo, S., Gras, M. E., \& Bedin, L. (2017b). What Leads Subjective Well-Being to Change Throughout Adolescence? An Exploration of Potential Factors, Child Ind Res, 10, 33-56. https://doi.org/10.1007/s12187-015-9359-6

Govorova, E., Benítez, I., \& Muñiz, J. (2020). How Schools Affect Student Well-Being: A Cross-Cultural Approach in 35 OECD Countries. Frontiers in Psychology, 11, 431. https://doi.org/10.3389/fpsyg. 2020.00431

Gutman, L. M., \& Feinstein, L. (2008) Children's Well-Being in Primary School: Pupil and School Effects, London: Centre for Research on the Wider Benefits of Learning, Institute of Education. http://webar chive.nationalarchives.gov.uk/20130323005725/https://www.education.gov.uk/publications/eOrde ringDownload/WBL25.pdf

Halliday, A. J., Kern, M. L., \& Turnbull, D. A. (2019). Can physical activity help explain the gender gap in adolescent mental health? A cross-sectional exploration. Mental Health and Physical Activity, 16, 8-18. https://doi.org/10.1016/j.mhpa.2019.02.003

Hardy, S. A., Nelson, J. M., Moore, J. P., \& King, P. E. (2019). Processes of Religious and Spiritual Influence in Adolescence: A Systematic Review of 30 Years of Research. Journal of Research on Adolescence, 29(2), 254-275. https://doi.org/10.1111/jora.12486

Hartas, D. (2019). The social context of adolescent mental health and wellbeing: Parents, friends and social media. Research Papers in Education. https://doi.org/10.1080/02671522.2019.1697734

Hobza, V., Hamrik, Z., Bucksch, J., \& De Clercy, B. (2017). The family affluence scale as an indicator for socioeconomic status: Validation on regional income differences in the Czech republic. International Journal of Environmental Research and Public Health, 14, 1540. https://doi.org/10.3390/ijerph14121540

Howe, A. S., Skidmore, P. M., Parnell, W. R., Wong, J. E., Lubransky, A. C., \& Black, K. E. (2016). Cardiorespiratory fitness is positively associated with a healthy dietary pattern in New Zealand adolescents. Public Health Nutrition, 19(7), 1279-1287. https://doi.org/10.1017/S1368980015002566

Hunter, S. C., Houghton, S., \& Wood, L. (2015). Positive Mental Well-being in Australian Adolescents: Evaluating the Warwick-Edinburgh Mental Well-being Scale. The Australian Educational and Developmental Psychologist, 32(2), 93-104. https://doi.org/10.1017/edp.2015.12

Janssen, A., Leahy, A. A., Diallo, T. M. O., Smith, J. J., Kennedy, S. G., Eather, N., Mavilidi, M. F., Wagemakers, A., Babic, M. J., \& Lubans, D. R. (2020). Cardiorespiratory fitness, muscular fitness and mental health in older adolescents: A multi-level cross-sectional analysis. Preventive Medicine, 132, 05985. https://doi.org/10.1016/j.ypmed.2020.105985

Janssen, I., \& LeBlanc, A. G. (2010). Systematic review of the health benefits of physical activity and fitness in school-aged children and youth. International Journal of Behavioral Nutrition and Physical Activity, 7, 40. https://doi.org/10.1186/1479-5868-7-40

Jenkins, R. H., Shen, C., Dumontheil, I., Thomas, M. S. C., Elliott, P., Röösli, M., \& Toledano, M. B. (2020). Social networking site use in young adolescents: Association with health-related quality of 
life and behavioural difficulties. Computers in Human Behavior, 109, 106320. https://doi.org/10. 1016/j.chb.2020.106320

Kidger, J., Araya, R., Donovan, J., \& Gunnell, D. (2012). The Effect of the School Environment on the Emotional Health of Adolescents: A Systematic Review. Pediatrics, 129, 925-949. https://doi.org/ 10.1542/peds.2011-2248

Klocke, A., Clair, A., \& Bradshaw, J. (2014). International variation in child subjective well-being. Child Indicators Research, 7, 1-20. https://doi.org/10.1007/s12187-013-9213-7

Kowalski, K. C., Crocker, P. R. E., \& Kowalski, N. P. (1997). Convergent validity of the Physical Activity Questionnaire for Adolescents. Pediatric Exercise Science, 9, 342-352. https://doi.org/10.1123/ pes.9.4.342

Lazarides, R., \& Buchholz, J. (2019). Student-perceived teaching quality: How is it related to different achievement emotions in mathematics classrooms? Learning and Instruction, 61, 45-59. https://doi. org/10.1016/j.learninstruc.2019.01.001

Lemola, S., Perkinson-Gloor, N., Brand, S., Dewald-Kaufmann, J. F., \& Grob, A. (2015). Adolescents' electronic media use at night, sleep disturbance, and depressive symptoms in the smartphone age. Journal of Youth and Adolescence, 44(2), 405-418. https://doi.org/10.1007/s10964-014-0176-X

Lombardo, M., Aulisa, G., Padua, E., Annino, G., Iellamo, F., Pratesi, A., et al. (2019). Gender differences in taste and food habits. Nutrition \& Food Science, 50(1), 229-239. https://doi.org/10.1108/ NFS-04-2019-0132

Maenhout, L., Peuters, C., Cardon, C., \& S., Crombez, G. \& DeSmet, A. (2020). The association of healthy lifestyle behaviors with mental health indicators among adolescents of different family affluence in Belgium. BMC Public Health, 20, 958. https://doi.org/10.1186/s12889-020-09102-9

McKay, M. T., \& Andretta, J. R. (2017). Evidence for the Psychometric Validity, Internal Consistency and Measurement Invariance of Warwick Edinburgh Mental Well-being Scale Scores in Scottish and Irish Adolescents. Psychiatry Research, 255, 382-386. https://doi.org/10.1016/j.psychres.2017. 06.071

McKeown, A., \& Nelson, R. (2018). Independent decision making of adolescents regarding food choice. International Journal of Consumer Studies, 42, 469-477. https://doi.org/10.1111/ijcs.12446

Meade, T., \& Dowswell, E. (2016). Adolescents' health-related quality of life (HRQoL) changes over time: A three year longitudinal study. Health and Quality of Life Outcomes, 14, 14. https://doi.org/ 10.1186/s12955-016-0415-9

Melendez-Torres, G., Hewitt, G., Hallingberg, B., Anthony, R., Collishaw, S., Hall, J., Murphy, S., \& Moore, G. (2019). Measurement invariance properties and external construct validity of the short Warwick-Edinburgh mental wellbeing scale in a large national sample of secondary school students in Wales. Health and Quality of Life Outcomes, 17, 139. https://doi.org/10.1186/s12955-019-1204-Z

Moore, G. F., Anthony, R. E., Hawkins, J., Van Goodwin, J., Murphy, S., Hewitt, G., \& Melendez-Torres, G. J. (2020). Socioeconomic status, mental wellbeing and transition to secondary schools: Analysis of the School Health Research Network/Health Behaviour in School-aged Children survey in Wales. British Educational Research Journal, 46(5), 1111-1130. https://doi.org/10.1002/berj.3616

Moor, I., Kuipers, M. A. G., Lorant, V., Pfortner, “' T. K., Kinnunen, J. M., Rathmann, K., et al. (2019). Inequalities in adolescent self-rated health and smoking in Europe: Comparing different indicators of socioeconomic status. Journal of Epidemiology \& Community Health, 73, 963-970. https://doi. org/10.1136/jech-2018-211794

Murphy, J., Sweeney, M. R., \& McGrane, B. (2020). Physical Activity and Sports Participation in Irish Adolescents and Associations with Anxiety, Depression and Mental Wellbeing. Findings from the Physical Activity and Wellbeing (Paws) Study. Physical Activity and Health, 4(1), 107-119. https:// doi.org/10.5334/paah.58

Murillo, F. J., \& Hernández-Castilla, R. (2011). Factores escolares asociados al desarrollo socio-afectivo en Iberoamerica. RELIEVE Rev. Electron. Invest. Eval. Educ., 17, 2. https://doi.org/10.7203/relieve. 17.2.4007

Muthén, L. K., \& Muthén, B. O. (1998-2017). Mplus User's Guide. Eighth Edition. Los Angeles, CA: Muthén \& Muthén.

Naeemi, S., \& Tamam, E. (2017). The Relationship Between Emotional Dependence on Facebook and Psychological Well-Being in Adolescents Aged 13-16. Child Indicators Research, 10, 1095-1106. https://doi.org/10.1007/s12187-016-9438-3

National Sleep Foundation. (2019). Teens and Sleep. Available from: https://www.sleepfoundation.org/ articles/teens-and-sleep. 
Plenty, S., \& Mood, C. (2016). Money, Peers and Parents: Social and Economic Aspects of Inequality in Youth Wellbeing. Journal of Youth Adolesc, 45(7), 1294-1308. https://doi.org/10.1007/s10964-016-0430-5

Post-Skagegard, M., Samuelson, G., Karlstrom, B., Mohsen, R., Berglund, L., \& Bratteby, L. E. (2002). Changes in food habits in healthy Swedish adolescents during the transition from adolescence to adulthood. European Journal of Clinical Nutrition, 56(6), 532-538. https://doi.org/10.1038/sj.ejcn. 1601345

Quine, S., Bernard, D., Booth, M., Kang, M., Usherwood, T., Alperstein, G., \& Bennett, D. (2003). Health and access issues among Australian adolescents: A rural-urban comparison. Rural and Remote Health, 3(3), 245. https://doi.org/10.22605/RRH245

Rees, G., \& Dinisman, T. (2014). Comparing children's experiences and evaluations of their lives in 11 different countries. Child Indicators Research. https://doi.org/10.1007/s12187-014-9291-1

Rees, G., Bradshaw, J., Goswami, H., \& Keung, A. (2010). Understanding children's well-being: A national survey of young people's well-being. London: The Children's Society. http://www.york.ac. uk/inst/spru/research/pdf/Understanding.pdf

Ringdal, R., Bradley Eilertsen, M.-E., Bjørnsen, H. N., Espnes, G. A., \& Moksnes, U. K. (2018). Validation of two versions of the Warwick-Edinburgh Mental Well-Being Scale among Norwegian adolescents. Scandinavian Journal of Public Health., 46(7), 718-725. https://doi.org/10.1177/1403494817735391

Rosenman, R., Tennekoon, V., \& Hill, L. G. (2011). Measuring bias in self-reported data. International Journal of Behavioural and Healthcare Research, 2(4), 320-332. https://doi.org/10.1504/IJBHR. 2011.043414

Royal College of Paediatrics and Child Health. (2018) The health impacts of screen time: a guide for clinicians and parents. https://www.rcpch.ac.uk/resources/health-impacts-screen-time-guide-cliniciansparents

Selwyn, J. \& Riley, S. (2015). Measuring well-being: A literature review. Coram Voice. www.coramvoice. org.uk/sites/default/files/Measuring\%20Wellbeing\%20FINAL.pdf.

Shochat, T., Cohen-Zion, M., \& Tzischinsky, O. (2014). Functional consequences of inadequate sleep in adolescents: A systematic review. Sleep Medicine Reviews, 18(1), 75-87. https://doi.org/10.1016/j. smrv.2013.03.005

Silva, A., Teles, J., \& Fragaso, I. (2020). Health-related quality of life of Portuguese children and adolescents according to diet quality and food intake. Quality of Life Research 29(8), 2197-2207.

Simon, A., Owen, C., O'Connell, R., \& Brooks, F. (2018). Changing trends in young people's food behaviour and wellbeing in England in relation to family affluence between 2005 and 2014. Journal of Youth Studies, 21(5), 687-700. https://doi.org/10.1080/13676261.2017.1406599

Skardal, M., Western, I. M., Ask, A. M. S., \& Overby, N. C. (2014). Socioeconomic differences in selected dietary habits among Norwegian 13-14 year-olds: A crosssectional study. Food \& Nutrition Research, 58, 23590. https://doi.org/10.3402/fnr.v58.23590

Slavin, J. L., \& Lloyd, B. (2012). Health benefits of fruits and vegetables. Advances in Nutrition (Bethesda, Md.), 3(4), 506-516. https://doi.org/10.3945/an.112.002154

Stewart-Brown, S., Tennant, A., Tennant, R., Platt, S., Parkinson, J., \& Weich, S. (2009). Internal construct validity of the Warwick- Edinburgh mental well-being scale (WEMWBS): A Rasch analysis using data from the Scottish health education population survey. Health and Quality of Life Outcomes, 7(1), 15. https://doi.org/10.1186/1477-7525-7-15

Statham, J., \& Chase, E. (2010). Childhood wellbeing: A brief overview. Child Wellbeing Research Centre. www.gov.uk/government/uploads/system/uploads/attachment_data/file/183197/Child-Wellb eing-Brief.pdf.

Straatmann, V. S., Oliveira, A. J., Rostila, M., \& Lopes, C. S. (2016). Changes in physical activity and screen time related to psychological well-being in early adolescence: Findings from longitudinal study ELANA. BMC Public Health, 16, 977. https://doi.org/10.1186/s12889-016-3606-8

Taylor C. Wallace, Regan L. Bailey, Jeffrey B. Blumberg, Britt Burton-Freeman, C-y. Oliver Chen, Kristi M. Crowe-White, Adam Drewnowski, Shirin Hooshmand, Elizabeth Johnson, Richard Lewis, Robert Murray, Sue A. Shapses \& Ding Ding Wang (2020) Fruits, vegetables, and health: A comprehensive narrative, umbrella review of the science and recommendations for enhanced public policy to improve intake. Critical Reviews in Food Science and Nutrition, 60:13, 2174-2211. https://doi.org/ 10.1080/10408398.2019.1632258

Tedstone Doherty, D., \& Kartalova-O'Doherty, Y. (2010). Gender and self-reported mental health problems: Predictors of help seeking from a general practitioner. British Journal of Health Psychology, 15(Pt 1), 213-228. https://doi.org/10.1348/135910709X457423 
Tennant, R., Hiller, L., Fishwick, R., Platt, S., Joseph, S., Weich, S., Hiller, L., Parkinson, J., Secker, J., \& Stewart-Brown, S. (2007). The Warwick-Edinburgh Mental Wellbeing Scale (WEMWBS): Development and UK validation. Health Quality of Life Outcomes, 5, 63. https://doi.org/10.1186/ 1477-7525-5-63

The Children's Society. (2016). The Good Childhood Report 2016. https://www.childrenssociety.org.uk/ sites/default/files/pcr090_summary_web.pdf

Twenge, J. M., Krizan, Z., \& Hisler, G. (2017). Decreases in self-reported sleep duration among US adolescents 2009-2015 and association with new media screen time. Sleep Medicine, 39, 47-53. https:// doi.org/10.1016/j.sleep.2017.08.013

UNICEF Spain. (2012). Children's well-being from their own point of view. What affects the children's well-being in the first year of compulsory secondary education in Spain? Madrid: UNICEF Spain. https://isciweb.org/wp-content/uploads/2019/12/Childrens_subjective_well-being_Unicef_feb13. pdf

United Nations Human Rights, Office of the High Commissioner. (OHCHR). (1989). Convention on the Rights of the Child. https://www.ohchr.org/EN/ProfessionalInterest/Pages/CRC.aspx

Viner, R. M., Aswothikutty-Gireesh, A., Stiglic, N., Hudson, L. D., Goddings, A. L., Ward, J. L., \& Nicholls, D. E. (2019). Roles of cyberbullying, sleep, and physical activity in mediating the effects of social media use on mental health and wellbeing among young people in England: A secondary analysis of longitudinal data. Lancet Child \& Adolescent Health, 3(10), 685-696. https://doi.org/10. 1016/S2352-4642(19)30186-5

Watt, T. (2003). Are Small Schools and Private Schools Better for Adolescents' Emotional Adjustment? Sociology of Education, 76(4), 344-367. https://doi.org/10.2307/1519870

White, R. L., Parker, P. D., Lubans, D. R., MacMillan, F., Olson, R., Astell-Burt, T., \& Lonsdale, C. (2018). Domain-specific physical activity and affective wellbeing among adolescents: An observational study of the moderating roles of autonomous and controlled motivation. International Journal of Behavioral Nutrition and Physical Activity, 15, 87. https://doi.org/10.1186/s12966-018-0722-0

Winpenny, E. M., Penney, T. L., Corder, K., White, M., \& van Slujis, E. M. F. (2017). Change in diet in the period from adolescence to early adulthood: A systematic scoping review of longitudinal studies. International Journal of Behavioral Nutrition and Physical Activity, 14(60). https://doi.org/10. 1186/s12966-017-0518-7

Wu, X. Y., Zhuang, L. H., Li, W., Guo, H. W., Zhang, J. H., Zhao, Y. K., et al. (2019). The influence of diet quality and dietary behavior on health-related quality of life in the general population of children and adolescents: A systematic review and meta analysis. Quality of Life Research, 28(8), 1989-2015. https://doi.org/10.1007/s11136-019-02162-4

Yang, Y., \& Green, S. B. (2011). Coefficient Alpha: A Reliability Coefficient for the 21st Century? Journal of Psychoeducational Assessment, 29(4), 377-392. https://doi.org/10.1177/0734282911406668

Yonker, J. E., Schnabelrauch, C. A., \& Dehaan, L. G. (2012). The relationship between spirituality and religiosity on psychological outcomes in adolescents and emerging adults: A meta-analytic review. Journal of Adolescence, 35(2), 299-314. https://doi.org/10.1016/j.adolescence.2011.08.010

Young, L., Kolubinski, D. C., \& Frings, D. (2020). Attachment style moderates the relationship between social media use and user mental health and wellbeing. Heliyon, 6(6), e04056. https://doi.org/10. 1016/j.heliyon.2020.e04056

Zahra, J., Ford, T., \& Jodrell, D. (2014). Cross-sectional survey of daily junk food consumption, irregular eating, mental and physical health and parenting style of British secondary school children. Child: Care, Health and Development, 40(4), 481-491. https://doi.org/10.1111/cch.12068

Publisher's Note Springer Nature remains neutral with regard to jurisdictional claims in published maps and institutional affiliations. 


\section{Authors and Affiliations}

\section{Jenny Davison ${ }^{1}$ - Brendan Bunting ${ }^{1} \cdot$ Paul Connolly $^{2} \cdot$ Katrina Lloyd $^{3}$.} Laura Dunne ${ }^{3} \cdot$ Barbara Stewart-Knox ${ }^{4}$

1 School of Psychology, Ulster University, Cromore Road, Northern Ireland, County Londonderry BT52 1SA Coleraine, UK

2 Faculty of Arts and Social Sciences, FASS Building, Lancaster University, Lancaster LA1 4YL, UK

3 Centre for Evidence and Social Innovation, Queens University Belfast, University Road, Belfast BT7 1NN, Northern Ireland, UK

4 Division of Psychology, University of Bradford, Bradford BD7 1DP, West Yorkshire, UK 